\title{
Evidence-based surgical technique for medial unicompartmental knee arthroplasty
}

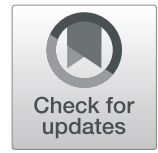

\author{
Tae Kyun Kim ${ }^{1 *}$ (D), Anurag Mittal ${ }^{1}$, Prashant Meshram², Woo Hyun Kim ${ }^{1}$ and Sang Min Choi ${ }^{1}$
}

\begin{abstract}
Unicompartmental knee arthroplasty (UKA) is a successful treatment modality in selected patients having advanced, single-compartment osteoarthritis of the knee. The bone and ligament preservation leading to shorter recovery periods, better functional outcomes, lower perioperative complication rates, and easier revision, if needed, are proposed as some of the advantages of UKA over total knee arthroplasty (TKA). Despite several advantages, UKA is reported to have higher failure rates as compared to TKA. The prosthesis failure of UKA is directly correlated to intraoperative technique-related factors like malpositioning of components and the inability to replicate the targetlimb alignment as per preoperative planning. An evidence-based surgical technique for UKA may help surgeons to avoid the intraoperative technique-related errors. The purpose of this paper is to describe a stepwise surgical technique for the fixed-bearing medial UKA.
\end{abstract}

Keywords: Unicompartmental knee arthroplasty, Knee replacement, UKA surgical technique, Persona partial knee

\section{Introduction}

The surgical options for patients with advanced osteoarthritis of a single compartment of the knee are unicompartmental knee arthroplasty (UKA), high tibial osteotomy (HTO), and total knee arthroplasty (TKA) [1]. UKA surgery is regarded as a less aggressive surgery than TKA, by virtue of the ligament preservation and reduced bone resection that it entails. As compared with TKA, UKA has been shown to have a shorter operative time, less blood loss, shorter hospital stays, earlier rehabilitation, improved gait kinematics, better range of motion, and the possibility of earlier return to sports [26]. In comparison to HTO, UKA offers a safe and efficient alternative with reduced postoperative pain, fewer postoperative complication, and revision especially in the older and less active population [7]. Notably, a 10year survivorship of $93 \%$ has been reported in a cohort of Korean patients undergoing UKA [8]. The

\footnotetext{
* Correspondence: osktk2000@yahoo.com

${ }^{1}$ TK Orthopedic Institution, 55 Dongpangyo-ro, Bundang-gu, Seongnam-si, Gyeonggi-do 13535, Republic of Korea

Full list of author information is available at the end of the article
}

contemporary emphasis to improve survivorship and function after UKA is on optimizing patient selection and improving surgical technique to reduce surgical errors.

In recent years, the number of UKAs performed has remained steady or shown rising trends globally [9-12]. One of the reasons for the increase in the number of UKAs performed globally is its expanding indications [13]. More recent inclusion criteria for medial UKA include advanced medial compartment osteoarthritis or osteonecrosis, functional anterior cruciate ligament $(\mathrm{ACL})$, preservation of the lateral compartment, passively correctible varus deformity of less than $10^{\circ}$, fixed-flexion deformity less than $15^{\circ}$, maximum knee flexion greater than $90^{\circ}$, and patient age of between 18 and 80 years [14-23]. Exclusion criteria include a diagnosis of inflammatory arthritis, hemochromatosis, hemophilia, symptomatic knee instability, multi-compartment disease, previously failed correctional osteotomy or ipsilateral UKA, immobility, or any other neurological condition affecting musculoskeletal function. Nonetheless, young age, high level of activity, obesity, presence of lateral osteophytes, chondrocalcinosis, and low-grade patellofemoral arthritis are not

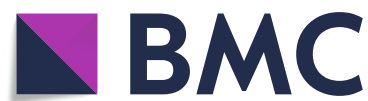

Part of Springer Nature (c) The Author(s). 2021 Open Access This article is licensed under a Creative Commons Attribution 4.0 International License, which permits use, sharing, adaptation, distribution and reproduction in any medium or format, as long as you give appropriate credit to the original author(s) and the source, provide a link to the Creative Commons licence, and indicate if changes were made. The images or other third party material in this article are included in the article's Creative Commons licence, unless indicated otherwise in a credit line to the material. If material is not included in the article's Creative Commons licence and your intended use is not permitted by statutory regulation or exceeds the permitted use, you will need to obtain permission directly from the copyright holder. To view a copy of this licence, visit http://creativecommons.org/licenses/by/4.0/. The Creative Commons Public Domain Dedication waiver (http://creativecommons.org/publicdomain/zero/1.0/) applies to the data made available in this article, unless otherwise stated in a credit line to the data. 
considered as absolute contraindications of UKA, as previously thought $[9,20]$.

Besides careful patient selection, another way to improve survivorship of UKA is by improving the surgical technique to avoid errors. The technical difficulties relating to limited surgical exposure and narrow margin of error in achieving surgical goals are one of the major reasons for surgeons hesitating to choose UKA over TKA. About $50 \%$ of the failures after UKA occur within the first 5 years of surgery $[24,25]$. These are attributed to surgical-technique-dependent failures which include aseptic loosening, polyethylene liner dislocation, and disease progression to another compartment [26-30]. While performing UKA surgery, the malpositioning of components and the inability to replicate the target-limb alignment as per preoperative planning have been shown to correlate with worse prosthesis survival and clinical outcomes [31-35]. While computer-assisted technologies, like navigation and robotics, are proposed to minimize the surgical errors, the evidence on their clinical efficacy is limited and there are concerns of low cost-effectiveness [36, 37].

Apart from the accuracy of bone resection and implant positioning, there are several key surgeon-controlled factors which are critical to the success of UKA that can be performed without computer assistance. These steps include, but are not limited to, the length of incision, approach and extent of exposure, cementation, and softtissue handling [38]. Thus, it becomes necessary for surgeons to adopt an evidence-based and meticulous surgical technique to optimize the results of UKA. Moreover, there is a learning curve ranging from 16 to 29 cases associated with conventional UKA that must be considered by novel surgeons [39, 40]. As the difficulties in adopting a new procedure have been highlighted in the past, an account of a stepwise approach to perform UKA may help surgeons to adopt this surgery in their practice [41]. To the best of our knowledge, there are no scientific articles in the literature describing an evidencebased surgical technique of UKA with a contemporary fixed-bearing UKA design. The purpose of this paper is to describe a stepwise surgical technique based on the available scientific evidence for the medial UKA using the Persona ${ }^{\circ}$ Partial Knee (PPK, Zimmer, Warsaw, IN, USA) system.

\section{Surgical technique}

We perform fixed bearing medial UKA (PPK) in patients having bone on bone arthritis of medial compartment of knee with normal lateral compartment and passively correctible deformities as described above. Launched in 2017, PPK features an anatomical tibial tray for maximal bone coverage without overhang, a conforming femur design and a fixed-bearing polyethylene. The surgical procedure is performed using a spacer block technique. The surgical technique for UKA using a PPK prosthesis as routinely performed by the senior author (TKK) has been discussed in the following nine steps with tips and pearls. The rationale of performing every step based on the scientific literature, when available, or anecdotal experience is also provided. The nine steps enlisted below are demonstrated in video1.

1. Exposure: (a) skin incision, (b) arthrotomy (c) dissection

2. Proximal tibial resection: (a) vertical-cut marking, (b) extramedullary (EM) jig placement and vertical cut, (c) horizontal cut

3. Distal femoral resection: (a) spacer block method, (b) gap check

4. Femoral sizing and final femoral preparation: (a) posterior rasping, (b) femoral size determination and finishing guide placement, (c) final preparation, (d) femoral trial test

5. Gap assessment

6. Tibial sizing and final tibial preparation

7. Trial test and polyethylene insert selection

8. Implant cementation: (a) tibial cementation, (b) femoral cementation, (c) final assessment and implantation

9. Placement of polyethylene insert and wound closure

\section{Exposure}

Adequate surgical exposure is critical in UKA for the visualization of bony and soft-tissue landmarks to avoid suboptimal positioning of the tibial and femoral components. Good exposure also avoids inadvertent tissue damage by forceful retraction. These factors, if not avoided, could indirectly result in inferior functional outcome and decreased survivorship of implants [42, 43].

\section{Skin incision}

The patient is laid supine with the knee in $30^{\circ}$ of flexion and skin marking is done (Fig. 1a). Alternate long and short transverse markings should be made on the vertical skin marking at a distance of around $2 \mathrm{~cm}$ which will be helpful in the closure of the skin at the end of surgery and avoid dog ears. After skin markings, an incision just medial to the midline is made extending from the superior pole of the patella to a point medial to the tibial tubercle (approximately $10-12 \mathrm{~cm}$ ). In contrast to a more medial incision, the above-mentioned incision will facilitate exposure for a subsequent revision to TKA, if necessary. Also, the tibial tuberosity can be seen easily and used as a landmark for tibial component rotation with a midline incision. The incision should be optimal (not minimal), long enough for easy visualization of the cruciate ligaments, medial tibial plateau, lateral compartment, patellofemoral 

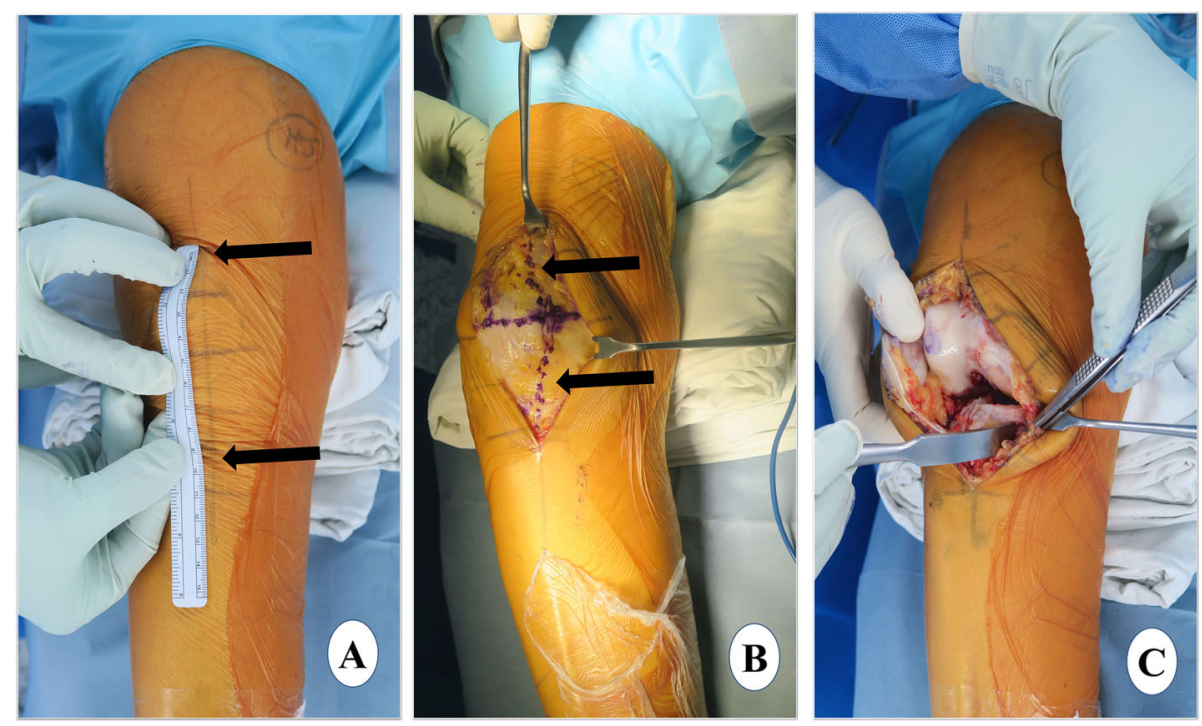

Fig. 1 Exposure. a skin marking. Arrows show the extent of incision from the superior pole of the patella to a point medial to the tibial tubercle. Ruler shows the length of the incision, $\mathbf{b}$ arthrotomy marking, and $\mathbf{c}$ medial envelope development

articulation, vertical line for the tibial cut, and placement of a bent Hohman retractor, $\mathrm{Z}$ retractor and extramedullary guide. The incision may have to be extended according to the amount of fat, build of the patient, and muscle tone and deformity in the knee.

\section{Arthrotomy}

The medial subcutaneous tissue is dissected, and the medial skin flap is retracted with superiorly and medially placed retractors. The arthrotomy line is marked, and it will be helpful to make a horizontal mark in the middle of the patella which will later allow for an accurate closure of the joint capsule. A medial parapatellar arthrotomy is performed extending from the superior pole of the patella curving down distally around the patella and patellar tendon (Fig. 1b). It is advisable to leave $1 \mathrm{~cm}$ of tendon attached to the patella for easy capsule closure.

\section{Dissection}

The lateral prepatellar fat pad is removed for better exposure of the cruciate ligaments and lateral compartment. The anterior one third of the medial meniscus is excised at the menisco-synovial junction using a sharp knife. Then, with slow and continued external rotation of the tibia, a medial envelope comprising the superficial medial collateral ligament (MCL) and capsule is created with a $1 \mathrm{~cm}$-wide, curved osteotome (Fig. 1c). The same osteotome is placed in the posteromedial corner of the proximal tibia. The deep MCL release is completed with electrocautery. Although controversial, we believe that deep MCL release similar to that in TKA should be considered in UKA also because it allows the placement of a $\mathrm{Z}$ retractor protecting the superficial MCL $[44,45]$ This also provides a good exposure of the medial tibial plateau for easy instrumentation and cementation. With the knee in extension and the patella everted, patelloplasty is performed which involves the demarcation of the patellar rim with the help of electrocautery and removal of osteophytes.

The knee is then flexed to $120^{\circ}$. The patella is retracted, and the osteophytes from the medial femoral condyle are removed. The femoral attachment of the MCL is retracted, and the osteophytes underneath are removed with the help of a 1-cm, straight osteotome and a rongeur. The osteophytes from both margins of the intercondylar notch and around the anterior cruciate ligament (ACL) are removed with the same instruments. All the osteophytes should be removed before balancing the flexion and extension space. Osteophyte removal will reveal the true deformity of the knee and accurate sizing of the femoral component will be possible. After osteophyte removal, at the time of exposure, the joint should be examined and inspected for the following: the ACL should be functionally intact, there should be bone-on-bone osteoarthritis on the medial compartment, a low grade of patellofemoral arthritis is acceptable, the lateral compartment cartilage should be full thickness, and minimal lateral osteophytes can be tolerated.

\section{Proximal tibial resection}

While performing UKA, the proximal tibial cut is one of the most critical steps, which, if not performed precisely, increases the risk of tibial prosthesis malalignment. This is even more important while using the extramedullary guide and spacer block technique compared to an intramedullary (IM) guided technique due to the possibility 
of transferring a tibial malalignment to a femoral malalignment [46].

\section{Vertical-cut marking}

For the lateral extent (sagittal) of the tibial cut, marking is done with the help of electrocautery. The cut starts posteriorly just medial to the posterior cruciate ligament (PCL) attachment. It extends anteriorly, violating up to the medial quarter of the fibers of the ACL which do not affect the function of the ACL. Further, the cut runs anteriorly to the medial tibial spine and finally to the medial one third of the tibial tuberosity (Fig. 2a). This marking sets the tibial component rotation. A blunt-tip reciprocating blade is preferred to make this cut in order to avoid damaging the posterior neurovascular structures. While leaving a flake of cortical bone posteriorly, the vertical cut should run in the anterior to posterior direction. The notch osteophyte removal done previously ensures that the blade of the reciprocating saw is parallel to the femoral condyle and as close to the tibial spine as possible. The cut should be as lateral as possible without violating the integrity of the ACL to the extent that it may result in functional laxity. This helps in accommodating the larger size of the tibial component and thereby avoids undersizing. It also leads to better central loading along with enough support for the tibial tray. These two factors will help to prevent the eccentric loading and subsequent tibial-plateau fracture or medialwall collapse.

\section{Extramedullary (EM) jig placement and vertical cut}

With the knee in $120^{\circ}$ of flexion and the tibia externally rotated, the anterior and middle tibial osteophytes are removed. With minimal patellar retraction, the tibia is levered out anteriorly with the help of a curved Hohmann retractor. It is important to put the retractor tip over a folded gauze placed posteriorly in the intercondylar notch just medial to PCL attachment to protect the
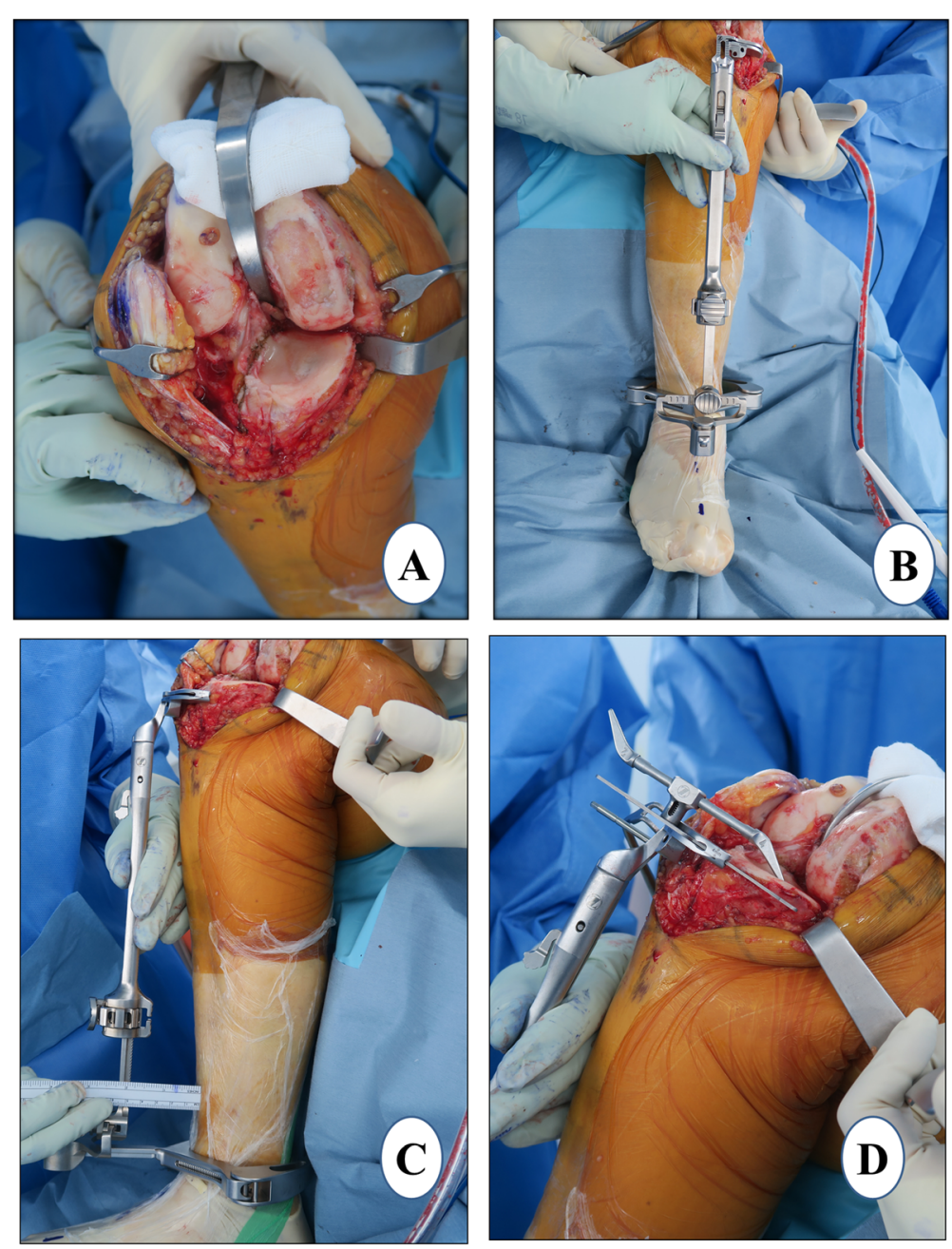

Fig. 2 Proximal tibial resection. a vertical-cut marking, b coronal alignment, $\mathbf{c}$ tibial slope setting, and $\mathbf{d}$ resection depth measurement 
posterior neurovascular structures. A Z retractor is applied over the medial tibial side to protect the posteromedial capsule and superficial MCL. Using a flexible ruler, the mid-point of the line joining the most prominent point of the medial and lateral malleoli is marked. A point $1 \mathrm{~cm}$ medial to the midpoint of the tibial surface is taken and extended distally to the first metatarsal and second toe, and proximally in line with the tibial shin. The EM jig is placed along this line which will help to adjust the coronal alignment of the tibial component (Fig. 2b). The slope of the tibial cut is chosen by adjusting the relative distance of the EM rod from the proximal and distal reference points, according to the preoperative planning (Fig. 2c). It is checked with the angel wing to make sure that the anterior and posterior medial tibial thickness being resected is equal and the cutting block is parallel to the medial tibial-plateau slope. In UKA, we generally cut along the natural slope $\left(7-9^{\circ}\right)$. Sometimes, the tibial-cut guide has a built-in posterior slope which a surgeon should be aware of (the PPK tibial-cut guide has $5^{\circ}$ of posterior slope built in). A central pin is placed in the EM jig to control the rotation of the cutting block with the coronal and sagittal alignment considered. The two pins are then placed connecting the proximal tibial cutting block to the tibia when all the parameters and resection depth are satisfactory. Subsequently, the vertical cut is made along the marked line described above. $A$ deeper vertical cut than the intended horizontal cut should be avoided to prevent creating a stress riser. In order to prevent a deeper than intended vertical cut, the lateral corner pin inserted into the sagittal cut slot on the tibial resection guide should be used a marker.

\section{Horizontal cut}

This cut will determine the depth of the tibial resection, coronal alignment, and the posterior slope. Generally, the thickness of the tibial cut is $4 \mathrm{~mm}$ which is achieved by placing a 4-mm stylus over the most damaged part on the medial tibial condyle and subsequently confirmed with the angel wing (Fig. 2d). We believe that a cut thicker than $4 \mathrm{~mm}$ exposes the cancellous metaphyseal bone which may lead to inferior bone prosthesis fixation and risk of early tibial subsidence and medial collapse. This depth is also appropriate for maintaining the native joint line and creating a pre-osteoarthritis alignment, a critical goal of UKA. While checking the gap balance, if the surgeon feels that the knee joint is too tight, then the tibial cut could be revised. Of note, a thinner cut may occasionally be desired if there is severe wear of the tibia. In this case, the 2-mm tip of the stylus can be used. Two pins used for temporarily fixing the tibia-cutting jig may be left in place which will facilitate the tibial cut revision, if necessary. With the $\mathrm{Z}$ retractor placed over the medial aspect of the tibia, the horizontal cut is made with a $1-\mathrm{cm}$ oscillating saw through a cutting block slot. It should be ensured that the retractor lies between the saw and the MCL, protecting the deep fibers of the ligament. A lateral straight retractor, a thin, metal device, can be inserted into the notch made by the vertical cut to prevent the saw blade from undermining the tibial eminence laterally.

At this stage, the EM tibial jig is detached. The resected part of tibial-plateau bone is removed with the help of a flat, wide osteotome. The knee may be flexed to $10-15^{\circ}$ to assist with the removal of the resected tibial plateau. The excised tibial plateau should be examined for the features of isolated anteromedial arthritis such as full-thickness cartilage loss anteriorly and relative preservation of the cartilage posteriorly. If this pattern is not observed, the status of the ACL is re-assessed. The anterior and posterior thickness of the excised tibial plateau is measured; it should be equal and preferably be 4 $\mathrm{mm}$, indicating an optimal posterior slope. A spacer block preferably of $9 \mathrm{~mm}$ is inserted with an alignment guide to check the requisite coronal alignment, tibial slope, and the tightness in $5-10^{\circ}$ of flexion. It is recommended to use a 9-mm spacer block instead of an $8-\mathrm{mm}$ spacer block as a 9-mm spacer allows the surgeon intraoperative flexibility of $\pm 1 \mathrm{~mm}$ [47]. The thickness is correct when the 9-mm spacer block can slide easily in and out. If the 9-mm spacer block is too loose, use a thicker spacer block to fill the extension gap. If the 9-mm spacer block has to be firmly gripped to slide in and out, this is too tight, and additional tibial resection is required.

\section{Evidence}

Mechanical hip-knee-ankle axis The evidence suggests that $1-4^{\circ}$ of varus alignment should be the goal in UKA [48]. This will prevent overloading the lateral compartment and subsequent lateral compartment osteoarthritis which is one of the common reasons for UKA failure.

Tibial coronal alignment Inappropriate coronal alignment of the tibial component could place undue stress on both cortical and cancellous bone, which may compromise the stability and long-term survivorship of the prosthesis [49]. The clinical results tend to be poor when the tibial components are placed in varus coronal alignment [50]. As far as bone stress and contact pressure on the bone-metal interface are concerned, a previous study has found that a slight valgus is the most stable inclination for the tibial component of UKA [51]. The coronal alignment of the UKA tibial and femoral components does not affect the FTA, as long as the joint line is maintained [52]. 
Tibial component rotation During normal flexion, the tibia rotates internally around $20^{\circ}$. The lateral compartment moves posteriorly more or less double the distance than the medial compartment [53]. The tibial rotation during range of motion is similar in osteoarthritic knees and knees after UKA [53]. Thus, a neutral rotation in extension and a $20^{\circ}$ external rotation in flexion indicates the ideal position of the tibial component. Theoretically, a rotation around $10^{\circ}$ could be appropriate for optimal knee kinematics neither in flexion nor extension [54]. However, in clinical studies, a tibial component axial rotation within $3^{\circ}$ of external rotation to $3^{\circ}$ of internal rotation has been correlated with significantly better clinical outcomes and functional scores $[54,55]$.

Tibial slope The tibial slope is an important factor that controls tibial translation during weight-bearing with an unconstrained implant design such as PPK. The posterior tibial slope is important for knee stability. A slight increase of the posterior tibial slope has often been preferred to promote increased flexion and femoral rollback and to improve the stress distribution at the bonetibial component interface. A posterior slope of between $3^{\circ}$ and $7^{\circ}$ is recommended to balance between the risk of excessive translation on one hand with the risk of excessive stress and cruciate ligament avulsion on the other hand $[56,57]$.

Tibial resection depth If the medial tibial surface is moved distally either by cutting excess bone prior to placement of the tibial component or using a thin polyethylene insert, the mechanical axis of the lower extremity shifts medially [58]. This will increase the mechanical stress on the medial compartment (increase the FTA) and may cause aseptic loosening of the components. Thus, the depth of the tibial cut should be kept to a minimum possible amount.

\section{Distal femoral resection}

This femoral cut will define the coronal alignment of the femur. When the spacer block method is used for femoral preparation, the distal femoral cut is made according to the tibial cut. It should be noted that the thickness of the spacer block does not change the thickness of the femoral cut. The spacer, as the name
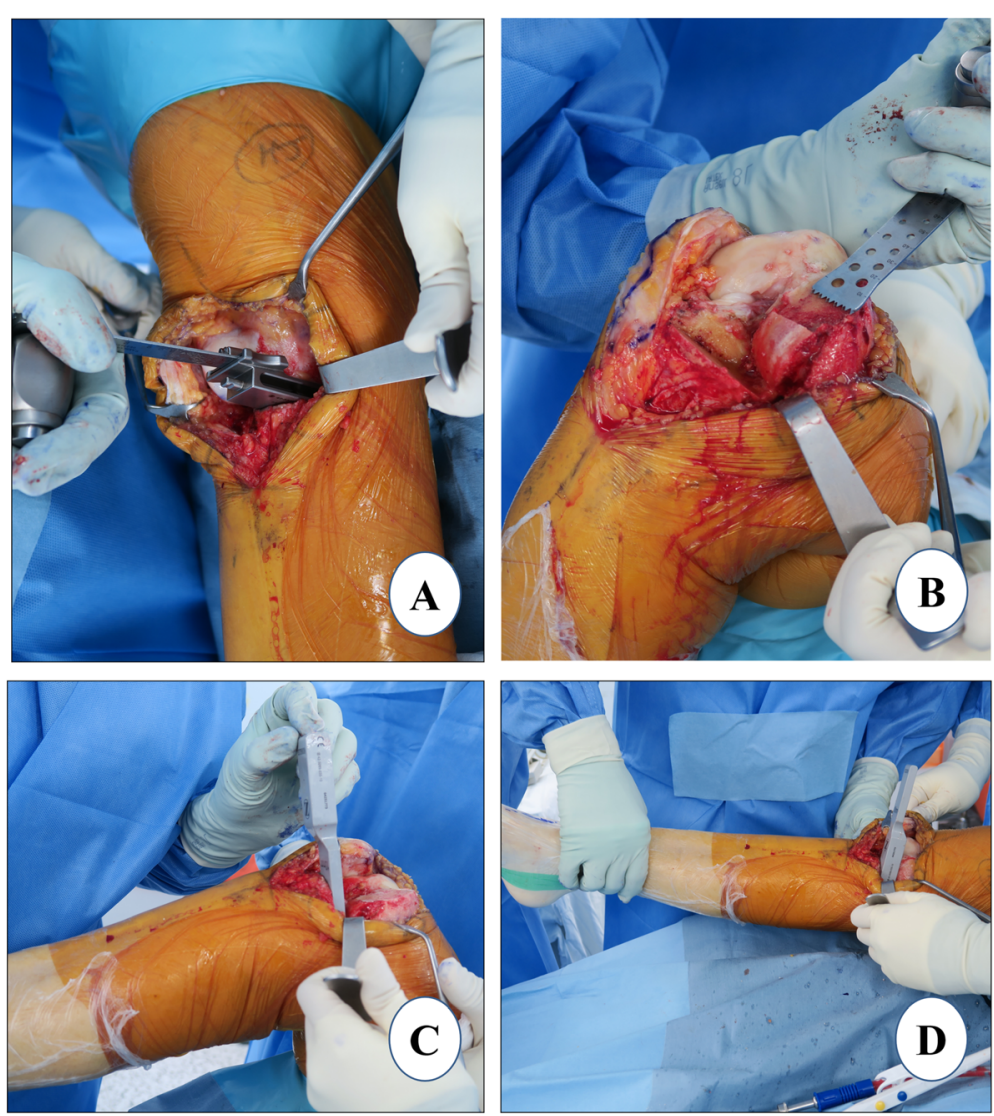

Fig. 3 Distal femoral resection. a spacer block method, b manual completion of distal femoral cut, $\mathbf{c}$ flexion gap check with thin blade, and $\mathbf{d}$ extension gap check with thick blade 
suggests, only fills the space between the tibia and femur to make the knee stable.

With the knee in extension, a spacer block of $9 \mathrm{~mm}$ or the thickness used earlier to confirm the tibial resection is inserted (Fig. 3a). It is important to confirm that the spacer block is fully inserted and sitting flat on the resected tibia and in contact with the distal femur. Anterior femoral osteophytes, if found, should be removed. Care should be taken not to hyperextend the knee. The narrow blade of the $\mathrm{Z}$ retractor is placed underneath the superficial MCL to prevent injury (Fig. 3a). While making the cut, surgeons should be careful not to go laterally as it may injure the trochlear groove. It would be advisable to cut half of the distal femoral surface with the spacer block in situ and the rest of the cut could be completed freehand using a wide, oscillating saw (Fig. $3 b)$. The knee could be placed in mid-flexion while completing the remaining posterior half cut to prevent damage to the posterior neurovascular bundles.

\section{Gap check}

The flexion gap is measured in about $100^{\circ}$ flexion using the thin blade of the gap checking device that matches the spacer block thickness used for cutting the distal femur (Fig. 3c). The extension gap is measured with the thick blade of this device (Fig. 3d). The extension gap should be measured in $5-10^{\circ}$ of flexion as posterior structures become tight in extension and may result in underestimation. Confirmation of the correct gap is assessed subjectively by checking whether a thicker gap checker is difficult to insert and a thinner gap checker is loose. It is important to ensure a slight undercorrection of the limb alignment and have at least $2 \mathrm{~mm}$ of laxity in extension as well as in flexion.

\section{Evidence}

An intramedullary guide and spacer block method are two techniques used in UKA to make the distal femoral cut. The spacer block technique aligns the distal resection of the femur parallel to the tibial resection in extension. The intramedullary technique requires perforation of the trochlea for guide placement, which, unlike TKA, is not replaced with a part of prosthesis in UKA. Extramedullary (EM) techniques avoid cannulating the medullary canals of the femur or tibia, diminishing the chances of marrow emboli and bleeding from the canal [59]. In a retrospective study, a $92.2 \%$ survival rate at a mean of 5.7 years' follow-up was observed using EM
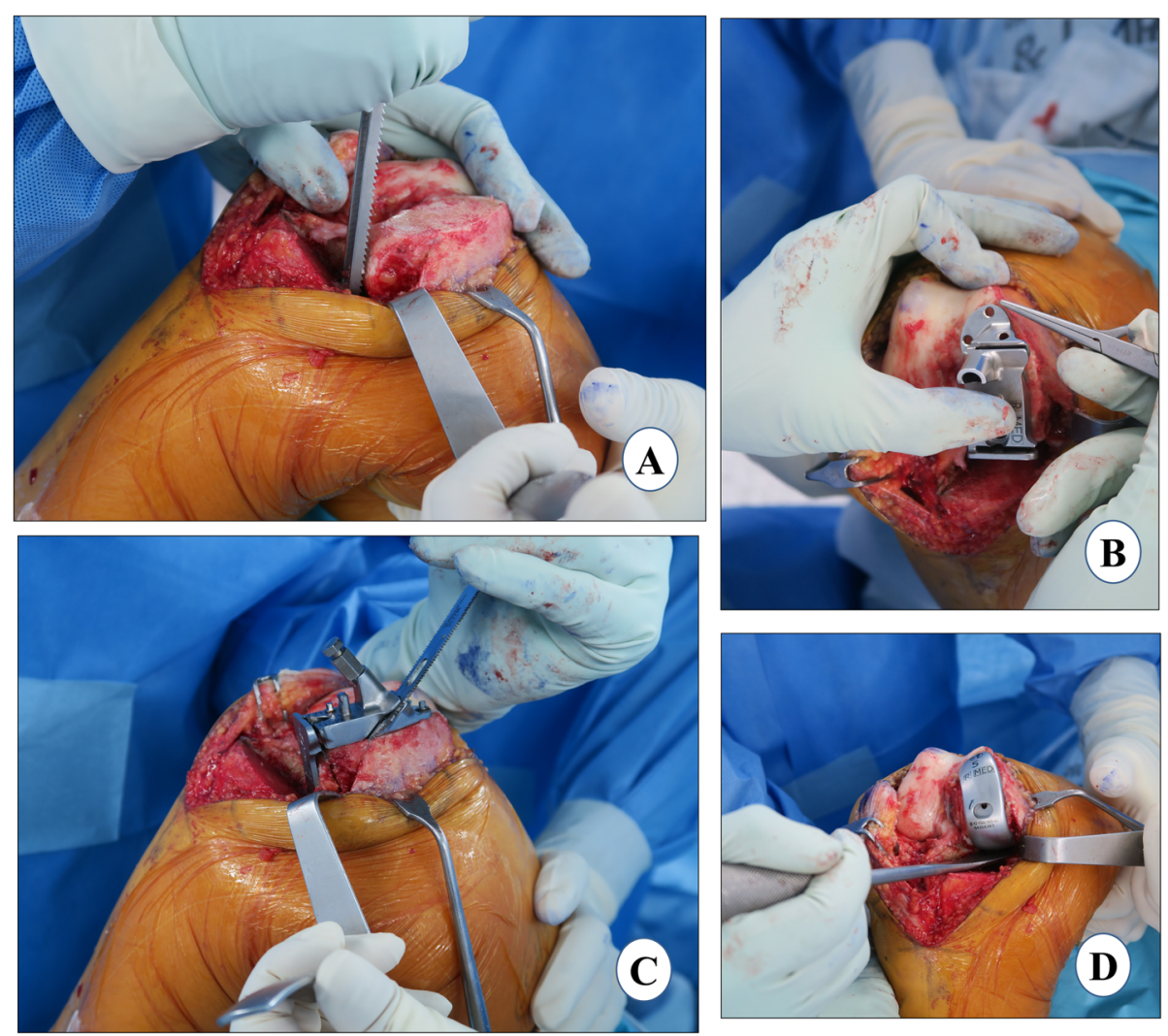

Fig. 4 Femoral sizing and final femoral preparation. a posterior rasping, b femoral finishing guide placement, c posterior femoral cut, and chamfer cut, and $\mathbf{d}$ femur trial 
tibial and femoral guides in 128 UKAs [60]. Both techniques have been shown to result in similar soft-tissue balancing and femoral alignment [61, 62]. Thus, we believe that the spacer block method is a better alternative.

\section{Femoral sizing and final femoral preparation Femoral sizing}

If the flexion gap is tight, any intact cartilage in the posterior femoral condyle should be rasped to anteriorize the femoral component (Fig. 4a). With the knee in $\sim 100^{\circ}$ of flexion, the femoral final "finishing" guide is placed on the resected distal femoral surface and the retained posterior condyle in order to assess the appropriate femoral size (Fig. 4b). The profile of each femoral finishing guide matches the location and profile of the corresponding femoral component anteriorly and distally. The guide should be lateralized as far as possible, aligning to the lateral border of the medial femoral condyle to avoid impingement on the intercondylar notch. This will increase the likelihood of the tibial component to properly track with the femur in extension and prevent patellofemoral impingement [63]. When properly sized, there should be a rim of at least $2 \mathrm{~mm}$ of exposed bone, anterior and medial to the femoral finishing guide (Fig. 4b). When confused between two subsequent femoral component sizes, the surgeon should choose the smaller size to prevent overhang which can lead to patellar impingement. The posterior edge of the guide should be parallel to the proximal tibial cut surface which can be ensured by insertion of the thin side of the flexion/ extension gap checker underneath the femoral finishing guide. This is important to prevent femur-tibia prosthesis divergence. Flexion malalignment of the femoral component should be avoided, because it could lead to adverse contact stress on the polyethylene insert and articular cartilage of the lateral compartment [64].

\section{Final preparation}

Once, the desired position is achieved, the finishing femoral guide is secured with three pins. Anterior peg-hole preparation is performed, and a lug rod is placed to provide support for the cutting block. Then, posterior peghole preparation is performed. The posterior femoral and posterior chamfer cuts are executed sequentially using the reciprocating saw with the $\mathrm{Z}$ retractor placed to protect the MCL (Fig. 4c). Again, it is advisable to carry out these cuts only partially with the guide, the rest should be done freehandedly. The trial component is fitted to confirm the correct femoral size (Fig. $4 \mathrm{~d}$ ). If the uncovered bone posteriorly is more than $2 \mathrm{~mm}$, the bone is removed using the posterior-curved osteotome.

\section{Gap assessment}

The residual meniscus is resected, osteophytes are removed, and the residual bone fragment of the medial tibial plateau is completely cut. The flexion (Fig. 5a) and the extension (Fig. 5b) gaps are confirmed to be equal using gap blocks which are usually 9 or $10 \mathrm{~mm}$ thick. If both flexion and extension gaps are too tight, a revision of the proximal tibia cut of $2 \mathrm{~mm}$ should be considered. The PPK prosthesis system has a 2-mm cutting guide which could be applied over the headless trocar pins of the tibia to revise the tibial cut precisely by $2 \mathrm{~mm}$ in thickness. If only the flexion gap is tight, a revision cut to increase the posterior slope of tibia is considered. In the authors' experience, such mismatch of the flexionextension gap rarely occurs provided that the previous steps are executed meticulously.

\section{Tibial sizing and final tibial preparation}

An appropriate tibial sizer is inserted that best covers the resected proximal tibia in both the anteroposterior (AP) and the mediolateral dimensions (Fig. 6a). The tibial sizer should be placed flush to the medial cortex (Fig. $6 b)$. If the sizer overhangs, confirm that the vertical tibial
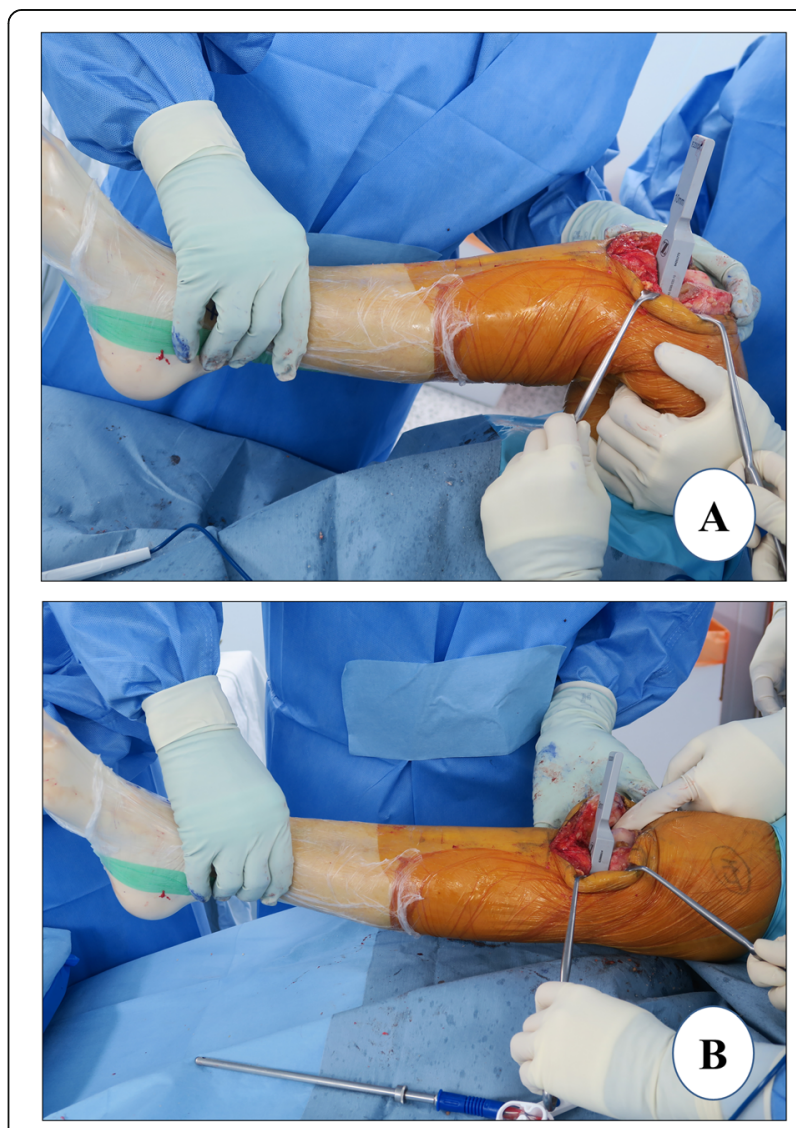

Fig. 5 Gap assessment. a flexion gap check and $\mathbf{b}$ extension gap check 

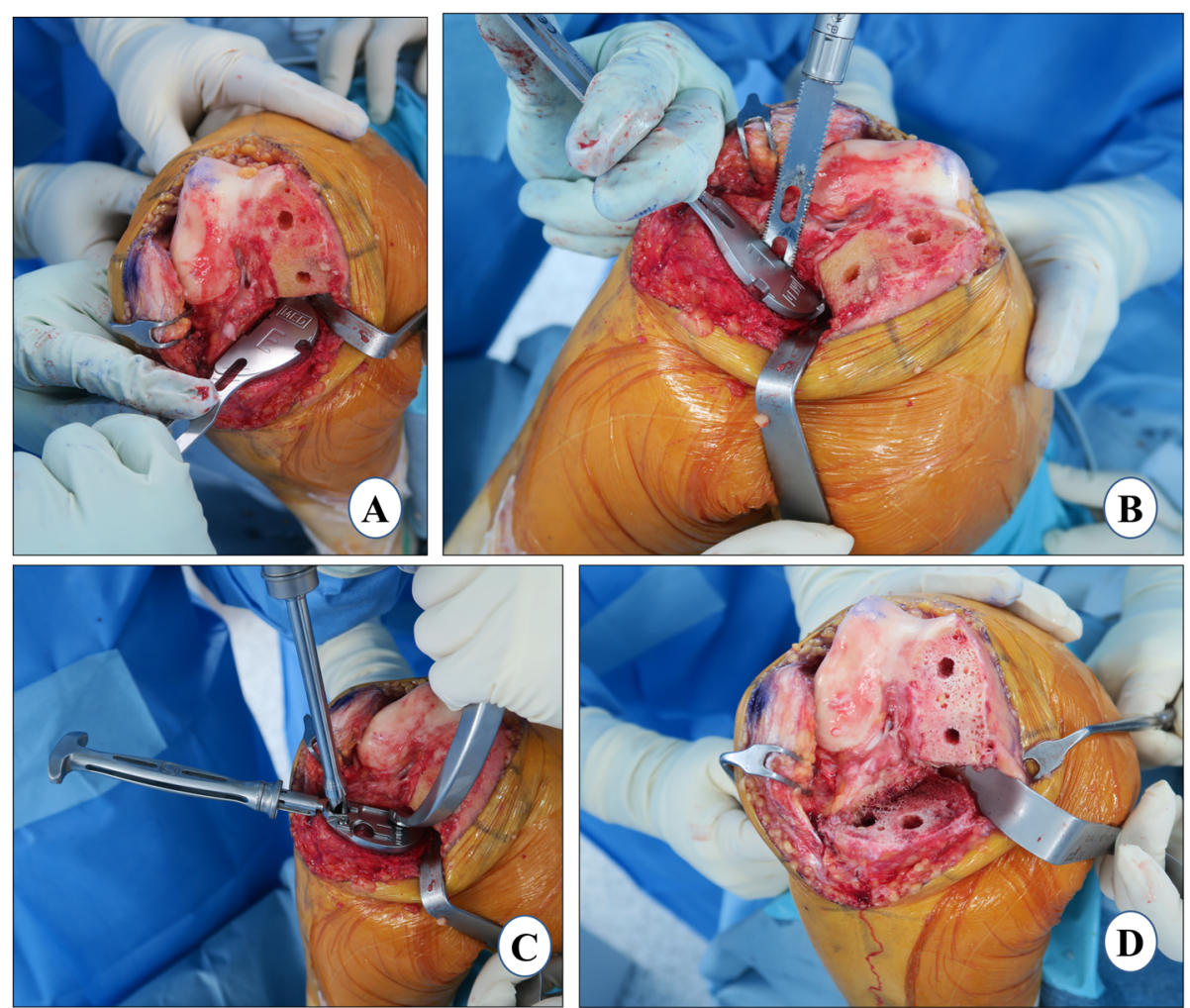

Fig. 6 Tibial sizing and final tibial preparation. a tibial sizing, $\mathbf{b}$ tibial component keel cut, $\mathbf{c}$ tibial preparation, and $\mathbf{d}$ tibial and femoral surfaces after peg holes

resection is as far lateral as possible; or use a smaller tibial size. The medial overhang may cause pain and should be avoided $[65,66]$. If the tibial sizer has a medial overhang of $2 \mathrm{~mm}$ or more and the AP dimension is correct, an additional removal of the lateral part of the remaining tibia should be considered. Once the appropriate size tibial trial is decided, it is placed flush to the tibial surface and the drilling (Fig. 6c) of the holes for the tibial component pegs is performed (Fig. 6d).

\section{Evidence}

The ideal scenario for optimal tibial component fixation is to have the best fit in the AP and mediolateral dimensions without impingement, to prevent tibial-plateau fracture or future component loosening. Unfortunately, this is often not possible, partly because of mismatch between the prosthesis design and bone anatomy [67]. Inadequate bony support of the proximal tibia to the tibial component is associated with its early subsidence or loosening [68]. A cortical bony coverage of the tibial component in the posteromedial and anterolateral region is strongly recommended for optimal fixation [69]. In addition, surgeons must avoid the tibial component overhang of $3 \mathrm{~mm}$ or more, as this severely compromises the outcome [68].

\section{Trial test and polyethylene insert selection}

When all the bone surfaces are prepared, a trial reduction is performed with the selected size of femoral, tibial, and polyethylene trials. The knee is manipulated through a full range of motion to determine the stability of the joint. A 2-mm end of the tension gauge/"amber stick" is inserted in flexion and extension to ensure that the gaps are not too tight (Fig. 7a). It is important to ensure a slight under-correction of the limb alignment and have appropriate ligamentous tension restored $(2-3 \mathrm{~mm}$ of laxity) in flexion and extension. A 2-mm blade should be able to insert easily but snugly, whereas $3-\mathrm{mm}$ blade insertion should be difficult. Before final implantation, the limb alignment is checked. Once the size and thickness of the components, and the limb alignment are confirmed, the trial components are removed. An irrigation of cut bone surfaces is done with $1 \mathrm{~L}$ of normal saline using a pulse lavage system to remove debris and fat. All cement-receiving bone surfaces are dried with a clean lap sponge. Of note, a 50-cc periarticular cocktail injection comprising $1 \mathrm{mg}$ epinephrine, $30 \mathrm{mg}$ ketorolac, 200 

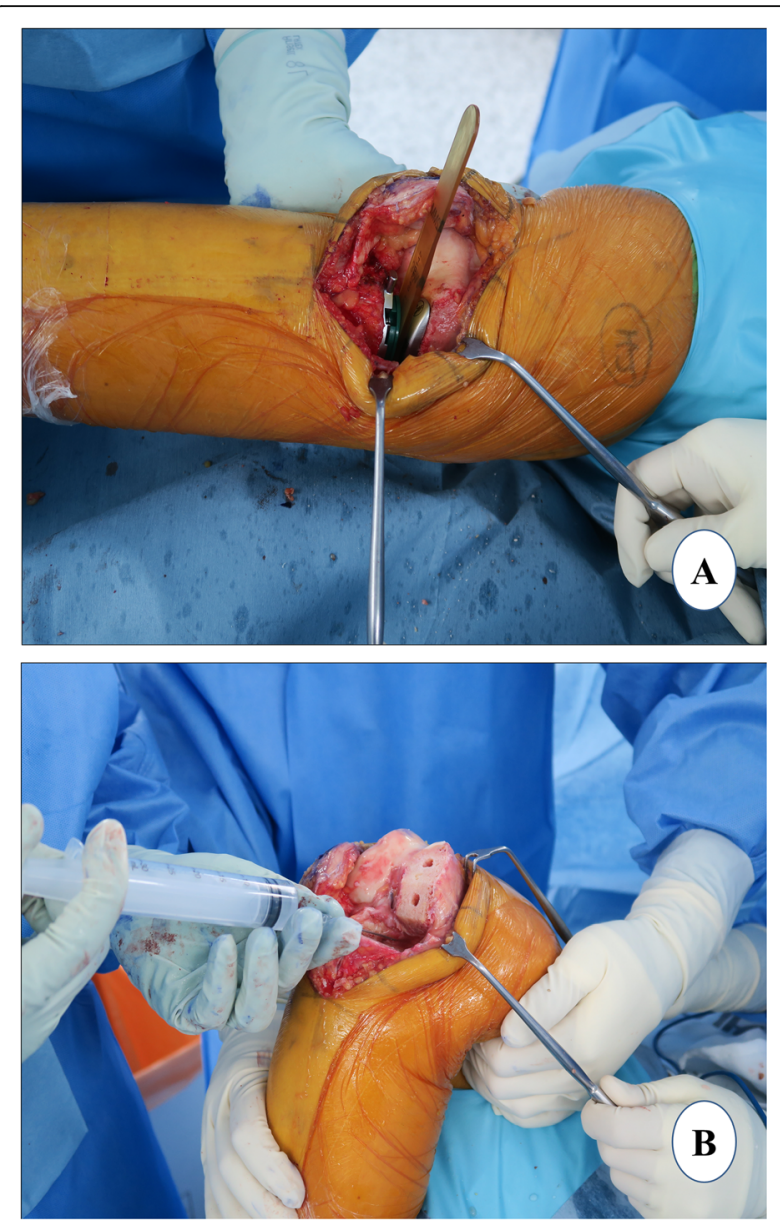

Fig. 7 Trial test and polyethylene insert selection. a trial test with $2 \mathrm{~mm}$ gauge and $\mathbf{b}$ periarticular injection and trial test

$\mathrm{mg}$ ropivacaine, $10 \mathrm{mg}$ morphine, $250 \mathrm{mg}$ cefuroxime, and the remaining normal saline is prepared just before surgery. A 25-cc volume of this periarticular injection cocktail is injected in the MCL and posterior capsule (Fig. 7b).

\section{Implant cementation}

A single 40-g unit of cement (Refobacin ${ }^{\odot}$ Bone Cement $R$, Zimmer Biomet, Warsaw, IN, USA) is used for implantation of both the components. The tibial cementation is immediately followed by femoral cementation and both are performed in a single cement-curing time duration.

\section{Tibia cementation}

While in flexion, the tibia is levered out anteriorly with the help of a retractor posteriorly with external rotation to facilitate proper cementation and implantation. A single 40-g unit of cement is vacuum mixed. As soon as cement properties permit, a thin layer of cement is applied over the entire underside of the tibial component and lateral flange. The cement should just overfill the pockets on the underside of the tray, up to $1 \mathrm{~mm}$ proud posteriorly and $2 \mathrm{~mm}$ proud anteriorly. Contamination of the component-cement interface must be avoided. With the flat nozzle of the cement gun, the tibia is cemented and pressurized manually with a broad, flat osteotome from the posterior to the anterior direction, striving for penetration of 3-4 mm (Fig. 8a). While placing the final component, the posterior portion of the tibial component is gently pressed down followed by the anterior portion of the component using a rasp handle. This maneuver will force excess cement anteriorly and prevent the posterior extrusion of cement where it becomes difficult to remove. The tibial component should be gently pressed and not hammered, as it may lead to fracture of the tibial plateau. Any excess cement should be removed from the posterior and anterior aspects of the tibia using a curved curette. It should be confirmed that all the cement has been removed from the proximal surface of the tibial component especially posteriorly as this will prevent the proper assembly of the polyethylene component.

\section{Femur cementation}

The femoral surface is dried, and a layer of cement is applied to the distal femur with the flat nozzle of cement gun. The cement is manually spread in the peg holes and posterior chamfer facet and pressurized, striving for a penetration of 3-4 mm (Fig. 8b). A thin layer of cement is also applied over the underside of the femoral component. With the leg in deep flexion, the posterior (longer) peg of the femoral component is inserted first followed by the anterior one. The femoral component is impacted with a mallet. It must be ensured that the anterior peg is engaged, and the component is fully seated (Fig. 8c). The excess cement is removed especially from the posterior aspect with the help of curette and wet gauze. A 1-mm thinner trial than the final bearing is inserted with a 2$\mathrm{mm}$ tension gauge to reduce excessive pressure on the cement which can result in cement leakage. It is then necessary to wait for the cement curing with the knee in extension (Fig. 8d). After the cement is cured, the trial insert is removed, and any remaining excess cement is curetted out before the final placement of the tibial bearing.

\section{Evidence}

Cement fixation allows the load to be distributed more evenly across the tibia, even with malalignment. Without cement fixation, there is an increased risk of point loading resulting in aseptic loosening [70]. Of note, a systematic review of 10 studies has reported good clinical outcomes with cementless UKA [71]. Nonetheless, we routinely use 

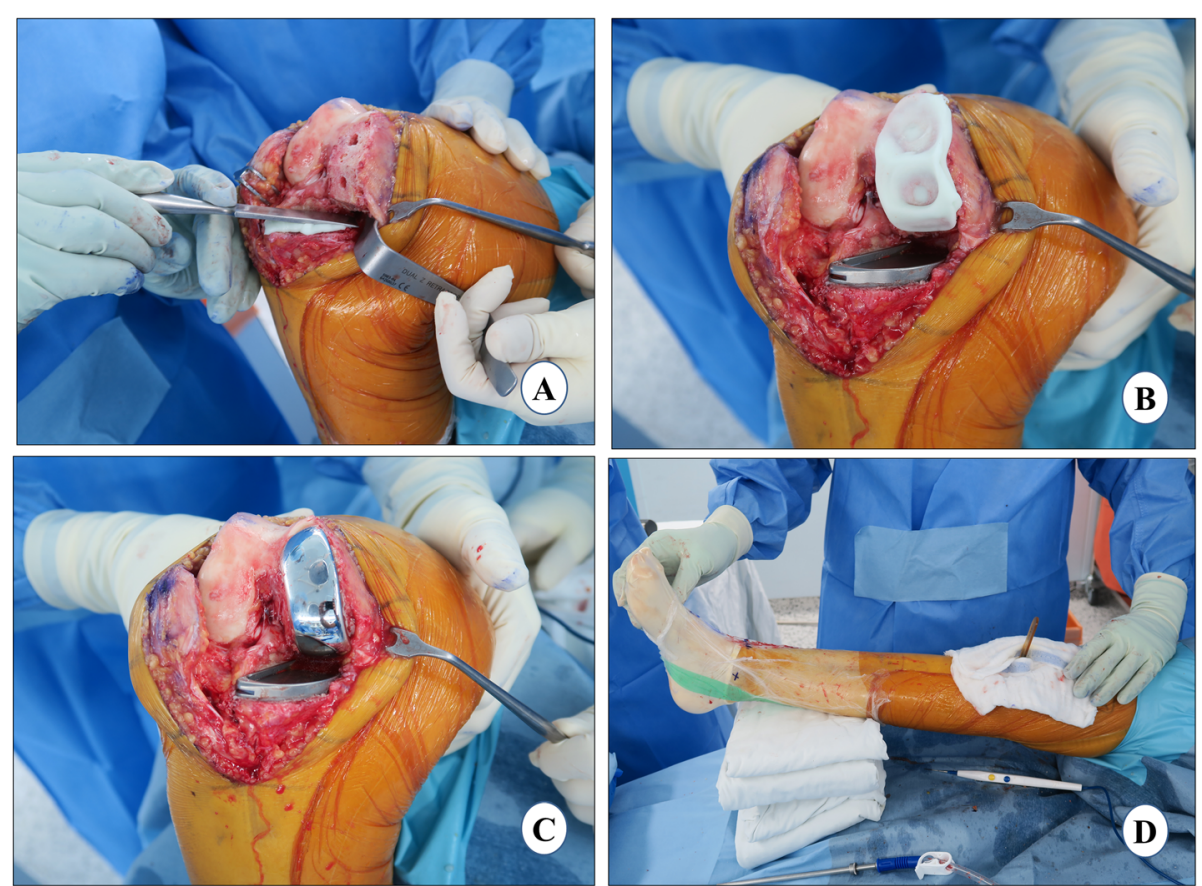

Fig. 8 Implant cementation. a tibial cementation, b femoral cementation, c Implantation, and $\mathbf{d}$ waiting for cement curing

cemented prosthesis for all our knee arthroplasties, and this is supported by long-term studies [32, 72-74] and over a decade of successful results in our patients.

\section{Polyethylene insert and wound closure}

The correct size and thickness of the final polyethylene bearing component is confirmed by checking the gap balance with the trial bearings in maximum flexion and extension. The tension gauge/"amber stick" is used to assess adequate laxity in flexion and extension. Then alignment is rechecked to verify that the joint has not been overcorrected. The knee is irrigated for the final time and the final tibial bearing is inserted with the knee in $60-70^{\circ}$ of flexion.

Another 25 cc of cocktail injection is injected into the medial capsule and quadriceps muscle (Fig. 9a). An airtight
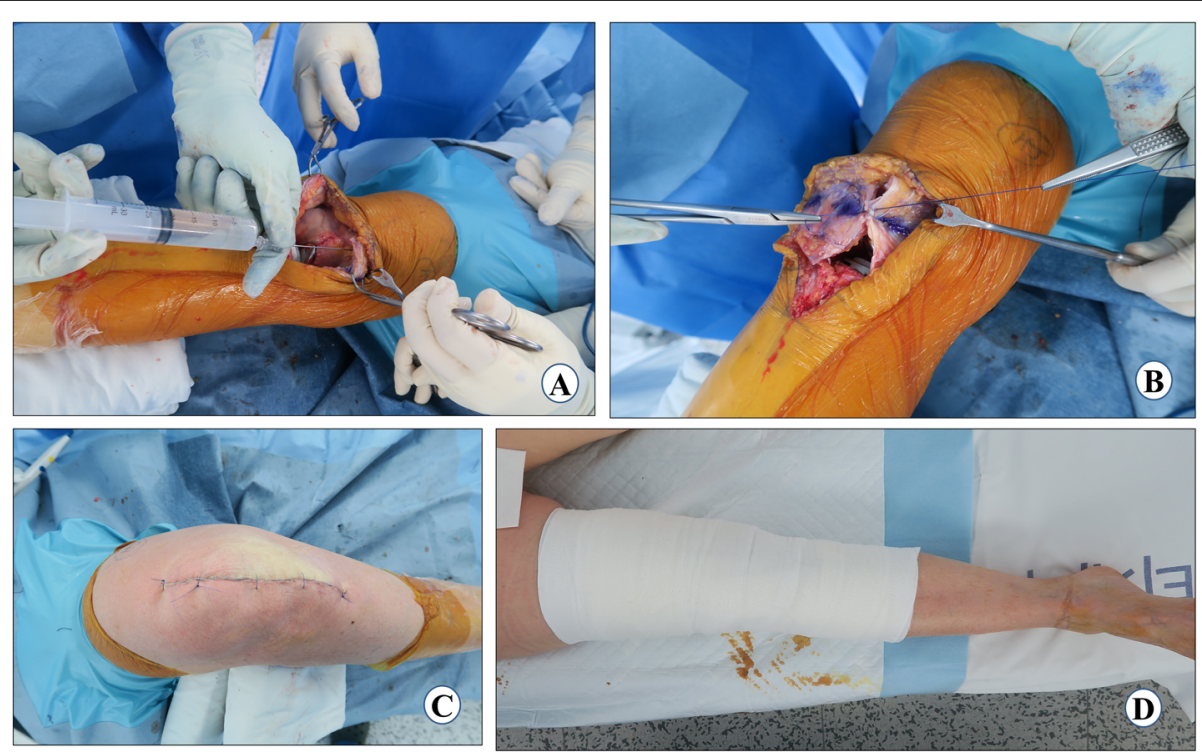

Fig. 9 Polyethylene insert and wound closure. a periarticular injection, b capsule closure, $\mathbf{c}$ skin closure, and $\mathbf{d}$ compression bandage and postoperative limb alignment 
wound closure should be the goal. The knee-joint capsule is closed with number 1 vicryl in approximately $30^{\circ}$ of knee flexion (Fig. 9b). Thirty milliliters of $3 \mathrm{~g}$ tranexamic acid in $30 \mathrm{ml}$ solution is injected into the knee joint [75] and then the knee is flexed to confirm the tight closure so that fluid is not leaking through any suture site. Next, subcutaneous sutures are applied meticulously with the help of 3-0 vicryl in $90^{\circ}$ of flexion. The skin is closed with prolene 3-0 using a subcuticular continuous suture technique (Fig. 9c). If a tourniquet was used, it is deflated at this point and the wound is inspected for any blood oozing. If not, then fibrin glue (Exofin, Chemence Medical, Alpharetta, GA, USA) is applied to seal the skin wound. An occlusive dressing material is applied followed by a compression bandage (Fig. 9d).

In addition to good surgical technique, postoperative rehabilitation plays an important role in the recovery of the patient after UKA. Rehabilitation should ideally start before surgery. The authors' preferred approach is to offer preoperative seminars and educational videos regarding the procedure, and future course [76]. Although controversial, preoperative rehabilitation can also play an important role in strengthening the quadriceps muscle of the patient and conditioning them for postsurgery physiotherapy. In the authors' experience, preoperative rehabilitation also reduces the anxiety of the patient. In general, the rehabilitation guidelines for UKA are similar to what is followed for TKA. However, the surgeon should be cautious when the patient is severely osteoporotic or more thick bone is resected from the tibia than recommended $(\sim 4 \mathrm{~mm})$. In these scenarios, rehabilitation should be less aggressive, and the knee should be protected with a brace and the use of crutches for ambulation. Most of the patients are able to return to routine daily activities by $2-3$ months and return to sports by 6 months [77]. Rehabilitation should achieve both physical and mental well-being, with a healthy, long life as the ultimate goal.

\section{Conclusions}

The adoption of a step-wise and meticulous approach is critical for successfully performing UKA surgery. Exposure, tibial cut, cementation, and wound closure are the most important aspects of the UKA surgical technique. The exposure should be optimal (not minimal) so that all the landmarks are visualized properly, and adequate space is available to prevent errors in bony cuts. In the spacer block method, the tibial cut plays a vital role in achieving preplanned limb alignment and component position (tibial as well as femoral). A varus of $1-4^{\circ}$ in the final mechanical hip-knee-ankle alignment is desirable for optimal results. Even distribution of the cement is important for adequate fixation. An airtight layer-bylayer wound closure is necessary for prevention of wound problems and early rehabilitation.

\section{Acknowledgements}

None

\section{Authors' contributions}

AM wrote the first draft of the manuscript. All authors reviewed and edited the manuscript and approved the final version of the manuscript.

\section{Funding}

This research received no specific grant from any funding agency in the public, commercial, or not-for-profit sectors.

\section{Availability of data and materials \\ Not applicable}

Ethics approval and consent to participate

Not applicable

\section{Consent for publication}

Not applicable

\section{Competing interests}

The authors declare that they have no competing interests.

\section{Author details}

${ }^{1}$ TK Orthopedic Institution, 55 Dongpangyo-ro, Bundang-gu, Seongnam-si, Gyeonggi-do 13535, Republic of Korea. '2Department of Orthopaedics, Johns Hopkins Medical Institute, 2360 West Joppa Road, Suite 306, Baltimore, MD 21093, USA.

Received: 11 September 2020 Accepted: 26 November 2020

Published online: 07 January 2021

\section{References}

1. Newman J, Pydisetty RV, Ackroyd C (2009) Unicompartmental or total knee replacement: the 15-year results of a prospective randomised controlled trial. J Bone Joint Surg Br 91(1):52-57. https://doi.org/10.1302/0301-620x. 91b1.20899

2. Wiik AV, Manning V, Strachan RK, Amis AA, Cobb JP (2013) Unicompartmental knee arthroplasty enables near normal gait at higher speeds, unlike total knee arthroplasty. J Arthroplasty 28(9 Suppl):176-178

3. Tu Y, Ma T, Wen T, Yang T, Xue L, Xue H (2020) Does unicompartmental knee replacement offer improved clinical advantages over total knee replacement in the treatment of isolated lateral osteoarthritis? A matched cohort analysis from an independent center. J Arthroplast. https://doi.org/ 10.1016/j.arth.2020.03.021

4. Migliorini F, Tingart M, Niewiera M, Rath B, Eschweiler J (2019) Unicompartmental versus total knee arthroplasty for knee osteoarthritis. Eur J Orthop Surg Traumatol 29(4):947-955. https://doi.org/10.1007/s00590-0182358-9

5. Kleeblad LJ, van der List JP, Zuiderbaan HA, Pearle AD (2018) Larger range of motion and increased return to activity, but higher revision rates following unicompartmental versus total knee arthroplasty in patients under 65: a systematic review. Knee Surg Sports Traumatol Arthrosc 26(6):18111822. https://doi.org/10.1007/s00167-017-4817-y

6. Friesenbichler B, Item-Glatthorn JF, Wellauer V, von Knoch F, Casartelli NC, Maffiuletti NA (2018) Short-term functional advantages after medial unicompartmental versus total knee arthroplasty. Knee 25(4):638-643. https://doi.org/10.1016/j.knee.2018.04.009

7. Cao Z, Mai X, Wang J, Feng E, Huang Y (2018) Unicompartmental knee arthroplasty vs high tibial osteotomy for knee osteoarthritis: a systematic review and meta-analysis. J Arthroplast 33(3):952-959. https://doi.org/10. 1016/j.arth.2017.10.025

8. Kim KT, Lee S, Kim JH, Hong SW, Jung WS, Shin WS (2015) The survivorship and clinical results of minimally invasive unicompartmental knee arthroplasty at 10-year follow-up. Clin Orthop Surg 7(2):199-206. https://doi. org/10.4055/cios.2015.7.2.199

9. Zuiderbaan HA, van der List JP, Kleeblad LJ, Appelboom P, Kort NP, Pearle AD et al (2016) Modern indications, results, and global trends in the use of unicompartmental knee arthroplasty and high tibial osteotomy in the treatment of isolated medial compartment osteoarthritis. Am J Orthop (Belle Mead NJ) 45(6):E355-Ee61 
10. Kahlenberg CA, Richardson SS, Gruskay JA, Cross MB (2020) Trends in utilization of total and unicompartmental knee arthroplasty in the United States. J Knee Surg. https://doi.org/10.1055/s-0040-1702189

11. Australian Orthopaedic Association: National Joint Replacement Registry, Annual Report 2019. [May 15, 2020]; Available from: https://aoanjrr.sahmri. com/annual-reports-2019

12. National Joint Registry for England, Wales and Northern Ireland, Annual Report 2018. [May 14, 2020]; Available from: https://www.hqip.org.uk/ resource/national-joint-registry-15th-annual-report-2018/\#.Xr4gCURLiHs

13. Crawford DA, Berend KR, Thienpont E (2020) Unicompartmental knee arthroplasty: US and global perspectives. Orthop Clin North Am 51(2):147159. https://doi.org/10.1016/j.ocl.2019.11.010

14. Greco NJ, Lombardi AV Jr, Price AJ, Berend ME, Berend KR (2018) Medial mobile-bearing unicompartmental knee arthroplasty in young patients aged less than or equal to 50 years. J Arthroplast 33(8):2435-2439. https://doi.org/ 10.1016/j.arth.2018.03.069

15. Hamilton TW, Choudhary R, Jenkins C, Mellon SJ, Dodd CAF, Murray DW et al (2017) Lateral osteophytes do not represent a contraindication to medial unicompartmental knee arthroplasty: a 15-year follow-up. Knee Surg Sports Traumatol Arthrosc 25(3):652-659. https://doi.org/10.1007/s00167016-4313-9

16. Kennedy JA, Matharu GS, Hamilton TW, Mellon SJ, Murray DW (2018) Age and outcomes of medial meniscal-bearing unicompartmental knee arthroplasty. J Arthroplast 33(10):3153-3159. https://doi.org/10.1016/j.arth. 2018.06.014

17. Walker T, Streit J, Gotterbarm T, Bruckner T, Merle C, Streit MR (2015) Sports, physical activity and patient-reported outcomes after medial unicompartmental knee arthroplasty in young patients. J Arthroplast 30(11): 1911-1916. https://doi.org/10.1016/j.arth.2015.05.031

18. Price AJ, Dodd CAF, Svard UGC, Murray DW (2005) Oxford medial unicompartmental knee arthroplasty in patients younger and older than 60 years of age. J Bone Joint Surg Br 87-B(11):1488-1492. https://doi.org/10. 1302/0301-620X.87B11.16324

19. Felts E, Parratte S, Pauly V, Aubaniac JM, Argenson JN (2010) Function and quality of life following medial unicompartmental knee arthroplasty in patients 60 years of age or younger. Orthop Traumatol Surg Res 96(8):861867. https://doi.org/10.1016/j.otsr.2010.05.012

20. Kim KT, Lee S, Lee JS, Kang MS, Koo KH (2018) Long-term clinical results of unicompartmental knee arthroplasty in patients younger than 60 years of age: minimum 10-year follow-up. Knee Surg Relat Res 30(1):28-33. https:// doi.org/10.5792/ksrr.17.025

21. Ventura A, Legnani C, Borgo E (2017) Unicompartmental knee replacement in patients aged 70 years and older. Muscles Ligaments Tendons J 7(4):611614. https://doi.org/10.11138/mltj/2017.7.4.611

22. Lunebourg A, Jiranek B (2019) Partial knee arthroplasty for older-aged patients. In: Argenson J-NA, Dalury DF (eds) Partial knee arthroplasty. Springer International Publishing, Cham, pp 63-68

23. Ode Q, Gaillard R, Batailler C, Herry Y, Neyret P, Servien E et al (2018) Fewer complications after UKA than TKA in patients over 85 years of age: a casecontrol study. Orthop Traumatol Surg Res 104(7):955-959. https://doi.org/10. 1016/j.otsr.2018.02.015

24. Epinette JA, Brunschweiler B, Mertl P, Mole D, Cazenave A (2012) Unicompartmental knee arthroplasty modes of failure: wear is not the main reason for failure: a multicentre study of 418 failed knees. Orthop Traumatol Surg Res 98(6 Suppl):S124-S130. https://doi.org/10.1016/j.otsr.2012.07.002

25. Aleto TJ, Berend ME, Ritter MA, Faris PM, Meneghini RM (2008) Early failure of unicompartmental knee arthroplasty leading to revision. J Arthroplast 23(2):159-163. https://doi.org/10.1016/j.arth.2007.03.020

26. van der List JP, MCDonald LS, Pearle AD (2015) Systematic review of medial versus lateral survivorship in unicompartmental knee arthroplasty. Knee 22(6):454-460. https://doi.org/10.1016/j.knee.2015.09.011

27. Thienpont $E$ (2017) Conversion of a unicompartmental knee arthroplasty to a total knee arthroplasty: can we achieve a primary result? Bone Joint J 99b(1 Supple A):65-69. https://doi.org/10.1302/0301-620x.99b1.Bji-2016-0272

28. Vasso M, Antoniadis A, Helmy N (2018) Update on unicompartmental knee arthroplasty: current indications and failure modes. EFORT Open Rev 3(8): 442-448. https://doi.org/10.1302/2058-5241.3.170060

29. Baker PN, Petheram T, Avery PJ, Gregg PJ, Deehan DJ (2012) Revision for unexplained pain following unicompartmental and total knee replacement. J Bone Joint Surg Am 94(17):e126. https://doi.org/10.2106/jbjs.k.00791
30. Bordini B, Stea S, Falcioni S, Ancarani C, Toni A (2014) Unicompartmental knee arthroplasty: 11-year experience from 3929 implants in RIPO register. Knee 21(6):1275-1279. https://doi.org/10.1016/j.knee.2014.02.012

31. Markel DC, Sutton K (2005) Unicompartmental knee arthroplasty: troubleshooting implant positioning and technical failures. J Knee Surg 18(2):96-101. https://doi.org/10.1055/s-0030-1248165

32. Mercier N, Wimsey S, Saragaglia D (2010) Long-term clinical results of the Oxford medial unicompartmental knee arthroplasty. Int Orthop 34(8):11371143. https://doi.org/10.1007/s00264-009-0869-z

33. Chatellard R, Sauleau V, Colmar M, Robert H, Raynaud G, Brilhault J (2013) Medial unicompartmental knee arthroplasty: does tibial component position influence clinical outcomes and arthroplasty survival? Orthop Traumatol Surg Res 99(4 Suppl):S219-S225. https://doi.org/10.1016/j.otsr.2013.03.004

34. Collier MB, Eickmann TH, Sukezaki F, McAuley JP, Engh GA (2006) Patient, implant, and alignment factors associated with revision of medial compartment unicondylar arthroplasty. J Arthroplast 21(6 Suppl 2):108-115. https://doi.org/10.1016/j.arth.2006.04.012

35. Hernigou P, Deschamps G (2004) Alignment influences wear in the knee after medial unicompartmental arthroplasty. Clin Orthop Relat Res 423:161165. https://doi.org/10.1097/01.blo.0000128285.90459.12

36. Moschetti WE, Konopka JF, Rubash HE, Genuario JW (2016) Can robotassisted unicompartmental knee arthroplasty be cost-effective? A Markov decision analysis. J Arthroplasty 31(4):759-765. https://doi.org/10.1016/j.arth. 2015.10.018

37. Gilmour A, MacLean AD, Rowe PJ, Banger MS, Donnelly I, Jones BG et al (2018) Robotic-arm-assisted vs conventional unicompartmental knee arthroplasty. The 2-year clinical outcomes of a randomized controlled trial. J Arthroplast 33(7s):S109-Ss15. https://doi.org/10.1016/j.arth.2018.02.050

38. Mofidi A, Plate JF, Lu B, Conditt MA, Lang JE, Poehling GG et al (2014) Assessment of accuracy of robotically assisted unicompartmental arthroplasty. Knee Surg Sports Traumatol Arthrosc 22(8):1918-1925. https:// doi.org/10.1007/s00167-014-2969-6

39. Hamilton WG, Ammeen D, Engh CA Jr, Engh GA (2010) Learning curve with minimally invasive unicompartmental knee arthroplasty. J Arthroplast 25(5): 735-740. https://doi.org/10.1016/j.arth.2009.05.011

40. Zhang Q, Zhang Q, Guo W, Liu Z, Cheng L, Yue D et al (2014) The learning curve for minimally invasive Oxford phase 3 unicompartmental knee arthroplasty: cumulative summation test for learning curve (LC-CUSUM). J Orthop Surg Res 9:81

41. Kim TK (2020) CORR ${ }^{\oplus}$ International-Asia-Pacific: adding another string to your bow. Clin Orthop Relat Res 478(6):1202-1204. https://doi.org/10.1097/ corr.0000000000001262

42. Berend KR, Lombardi AV Jr, Mallory TH, Adams JB, Groseth KL (2005) Early failure of minimally invasive unicompartmental knee arthroplasty is associated with obesity. Clin Orthop Relat Res 440:60-66. https://doi.org/10. 1097/01.blo.0000187062.65691.e3

43. Dalury DF, Dennis DA (2005) Mini-incision total knee arthroplasty can increase risk of component malalignment. Clin Orthop Relat Res 440:77-81. https://doi.org/10.1097/01.blo.0000185757.17401.7b

44. Vail T, Lang J, Sikes C (2012) Surgical techniques and instrumentation in total knee arthroplasty. In: Scott WN, Insall JN (eds) Surgery of the knee, 5th edn. Elsevier/Churchill Livingstone, Philadelphia, pp 1042-1099

45. Verdonk PC, Pernin J, Pinaroli A, Ait Si Selmi T, Neyret P (2009) Soft tissue balancing in varus total knee arthroplasty: an algorithmic approach. Knee Surg Sports Traumatol Arthrosc 17(6):660-666. https://doi.org/10.1007/ s00167-009-0755-7

46. Matziolis G, Mueller T, Layher F, Wagner A (2018) The femoral component alignment resulting from spacer block technique is not worse than after intramedullary guided technique in medial unicompartimental knee arthroplasty. Arch Orthop Trauma Surg 138(6):865-870. https://doi.org/10. 1007/s00402-018-2911-3

47. Zhang Q, Wang W, Liu Z, Yue D, Cheng L, Wang B et al (2020) A novel extramedullary technique to guide femoral bone preparation in mobile unicompartmental knee arthroplasty based on tibial cut and overall alignment. J Orthop Surg Res 15(1):92. https://doi.org/10.1186/s13018-02001598-6

48. Zuiderbaan HA, van der List JP, Chawla H, Khamaisy S, Thein R, Pearle AD (2016) Predictors of subjective outcome after medial unicompartmental knee arthroplasty. J Arthroplast 31(7):1453-1458. https://doi.org/10.1016/j. arth.2015.12.038 
49. Fang DM, Ritter MA, Davis KE (2009) Coronal alignment in total knee arthroplasty: just how important is it? J Arthroplast 24(6 Suppl):39-43. https://doi.org/10.1016/j.arth.2009.04.034

50. Swienckowski J, Page BJ 2nd. (1989) Medial unicompartmental arthroplasty of the knee. Use of the L-cut and comparison with the tibial inset method. Clin Orthop Relat Res 239:161-167

51. lesaka K, Tsumura H, Sonoda H, Sawatari T, Takasita M, Torisu T (2002) The effects of tibial component inclination on bone stress after unicompartmental knee arthroplasty. J Biomech 35(7):969-974. https://doi. org/10.1016/s0021-9290(01)00244-5

52. Kim SJ, Bae JH, Lim HC (2012) Factors affecting the postoperative limb alignment and clinical outcome after Oxford unicompartmental knee arthroplasty. J Arthroplast 27(6):1210-1215. https://doi.org/10.1016/j.arth. 2011.12.011

53. Casino D, Martelli S, Zaffagnini S, Lopomo N, lacono F, Bignozzi S et al (2009) Knee stability before and after total and unicondylar knee replacement: in vivo kinematic evaluation utilizing navigation. J Orthop Res 27(2):202-207. https://doi.org/10.1002/jor.20746

54. Iriberri I, Aragon JF (2014) Alignment of the tibial component of the unicompartmental knee arthroplasty, assessed in the axial view by CT scan: does it influence the outcome? Knee 21(6):1269-1274. https://doi.org/10. 1016/j.knee.2014.06.008

55. Liow MH, Tsai TY, Dimitriou D, Li G, Kwon YM (2016) Does 3-dimensional in vivo component rotation affect clinical outcomes in unicompartmental knee arthroplasty? J Arthroplast 31(10):2167-2172. https://doi.org/10.1016/j. arth.2016.03.003

56. Whiteside LA, Amador DD (1988) The effect of posterior tibial slope on knee stability after Ortholoc total knee arthroplasty. J Arthroplast 3(Suppl):S51S57. https://doi.org/10.1016/s0883-5403(88)80009-3

57. Hernigou P, Deschamps G (2004) Posterior slope of the tibial implant and the outcome of unicompartmental knee arthroplasty. J Bone Joint Surg Am 86(3):506-511. https://doi.org/10.2106/00004623-200403000-00007

58. Lewold S, Robertsson O, Knutson K, Lidgren L (1998) Revision of unicompartmental knee arthroplasty: outcome in 1,135 cases from the Swedish Knee Arthroplasty study. Acta Orthop Scand 69(5):469-474. https:// doi.org/10.3109/17453679808997780

59. Levine B, Rosenberg AG (2014) The simple unicondylar knee: extramedullary technique. Clin Sports Med 33(1):77-85. https://doi.org/10.1016/j.csm.2013. 06.003

60. Biswal S, Brighton RW (2010) Results of unicompartmental knee arthroplasty with cemented, fixed-bearing prosthesis using minimally invasive surgery. J Arthroplast 25(5):721-727. https://doi.org/10.1016/j.arth.2009.06.017

61. Matsumoto T, Muratsu H, Kubo S, Kuroda R, Kurosaka M (2013) Intraoperative joint gap kinematics in unicompartmental knee arthroplasty. Clin Biomech (Bristol, Avon) 28(1):29-33. https://doi.org/10.1016/j.clinbiomech. 2012.09.002

62. Fisher DA, Watts M, Davis KE (2003) Implant position in knee surgery: a comparison of minimally invasive, open unicompartmental, and total knee arthroplasty. J Arthroplast 18(7 Suppl 1):2-8. https://doi.org/10.1016/s08835403(03)00291-2

63. Kang KT, Son J, Koh YG, Kwon OR, Kwon SK, Lee YJ et al (2018) Effect of femoral component position on biomechanical outcomes of unicompartmental knee arthroplasty. Knee 25(3):491-498. https://doi.org/10. 1016/j.knee.2018.03.003

64. Park KK, Koh YG, Park KM, Park JH, Kang KT (2019) Biomechanical effect with respect to the sagittal positioning of the femoral component in unicompartmental knee arthroplasty. Biomed Mater Eng 30(2):171-182. https://doi.org/10.3233/bme-191042

65. Tiwari V, Meshram P, Park CK, Bansal V, Kim TK (2019) New mobile-bearing TKA with unique ball and socket post-cam mechanism offers similar function and stability with better prosthesis fit and gap balancing compared to an established fixed-bearing prosthesis. Knee Surg Sports Traumatol Arthrosc 27(7):2145-2154. https://doi.org/10.1007/s00167-01905430-5

66. Sharma G, Liu D, Malhotra R, Zhou YX, Akagi M, Kim TK (2017) Availability of additional mediolateral implant option during total knee arthroplasty improves femoral component fit across ethnicities: results of a multicenter study. JB JS Open Access 2(2):e0014. https://doi.org/10.2106/jbjs.oa.16.00014

67. Fitzpatrick C, FitzPatrick D, Lee J, Auger D (2007) Statistical design of unicompartmental tibial implants and comparison with current devices. Knee 14(2):138-144. https://doi.org/10.1016/j.knee.2006.11.005
68. Chau R, Gulati A, Pandit H, Beard DJ, Price AJ, Dodd CA et al (2009) Tibial component overhang following unicompartmental knee replacement—does it matter? Knee 16(5):310-313. https://doi.org/10.1016/j. knee.2008.12.017

69. Lee YS, Yun JY, Lee BK (2014) Tibial component coverage based on bone mineral density of the cut tibial surface during unicompartmental knee arthroplasty: clinical relevance of the prevention of tibial component subsidence. Arch Orthop Trauma Surg 134(1):85-89. https://doi.org/10.1007/ s00402-013-1895-2

70. Ritter MA, Meneghini RM (2010) Twenty-year survivorship of cementless anatomic graduated component total knee arthroplasty. J Arthroplast 25(4): 507-513. https://doi.org/10.1016/j.arth.2009.04.018

71. Campi S, Pandit HG, Dodd CAF, Murray DW (2017) Cementless fixation in medial unicompartmental knee arthroplasty: a systematic review. Knee Surg Sports Traumatol Arthrosc 25(3):736-745. https://doi.org/10.1007/s00167016-4244-5

72. Mittal A, Meshram P, Kim WH, Kim TK (2020) Unicompartmental knee arthroplasty, an enigma, and the ten enigmas of medial UKA. J Orthop Traumatol 21(1):15. https://doi.org/10.1186/s10195-020-00551-x

73. Winnock de Grave P, Barbier J, Luyckx T, Ryckaert A, Gunst P, Van den Daelen L (2018) Outcomes of a fixed-bearing, medial, cemented unicondylar knee arthroplasty design: survival analysis and functional score of 460 cases. J Arthroplast 33(9):2792-2799. https://doi.org/10.1016/j.arth. 2018.04.031

74. Alnachoukati OK, Barrington JW, Berend KR, Kolczun MC, Emerson RH, Lombardi AV Jr et al (2018) Eight hundred twenty-five medial mobilebearing unicompartmental knee arthroplasties: the first 10-year US multicenter survival analysis. J Arthroplast 33(3):677-683. https://doi.org/10.1016/j. arth.2017.10.015

75. Meshram P, Palanisamy JV, Seo JY, Lee JG, Kim TK (2020) Combined intravenous and intraarticular tranexamic acid does not offer additional benefit compared with intraarticular use alone in bilateral TKA: a randomized controlled trial. Clin Orthop Relat Res 478(1):45-54. https://doi. org/10.1097/corr.0000000000000942

76. Kim TK (2020) CORR ${ }^{\oplus}$ International - Asia-Pacific: closing the loop-focus early and often on your patients' postsurgical rehabilitation program. Clin Orthop Relat Res 478(10):2225-2227. https://doi.org/10.1097/CORR. 0000000000001475

77. Witjes S, Gouttebarge V, Kuijer PP, van Geenen RC, Poolman RW, Kerkhoffs GM (2016) Return to sports and physical activity after total and unicondylar knee arthroplasty: a systematic review and meta-analysis. Sports Med 46(2): 269-292. https://doi.org/10.1007/s40279-015-0421-9

\section{Publisher's Note}

Springer Nature remains neutral with regard to jurisdictional claims in published maps and institutional affiliations.

\section{Ready to submit your research? Choose BMC and benefit from:}

- fast, convenient online submission

- thorough peer review by experienced researchers in your field

- rapid publication on acceptance

- support for research data, including large and complex data types

- gold Open Access which fosters wider collaboration and increased citations

- maximum visibility for your research: over $100 \mathrm{M}$ website views per year

At $\mathrm{BMC}$, research is always in progress.

Learn more biomedcentral.com/submission 